\title{
A Retrospective Comparative Analysis Regarding Strategies for Early COVID-19 Pandemic Mitigation in the US and South Korea
}

\author{
Rohan Bhansali \\ Senior at Loudoun Academy of Science \\ Director at Connect AI \\ Ashburn, United States
}

\author{
Rahul Kumar \\ Senior at Loudoun Academy of Science \\ Director at Aluna Research Group \\ Ashburn, United States
}

\begin{abstract}
The purpose of this report is to retrospectively analyze and compare the early COVID-19 pandemic mitigation strategies of South Korea and the United States as the insights and knowledge gained can be applied to subsequent pandemics to minimize devastation. Additionally, this report will specifically give attention to the role of new emerging technologies in the detection, prevention, and treatment of this virus, as well as their role in the future and addresses early mitigation strategies that are implemented within two months of each country's first detected case. First, we present a basic historical background regarding the nature of pandemics, as well as previous early mitigation techniques and their respective outcomes. This contains a background regarding the characteristics of the severe acute respiratory syndrome coronavirus 2 (SARS-CoV-2) and the COVID-19 disease; additionally, we analyze the global spread of the virus prior to the imposition of universal travel bans. The second section provides comparative analysis regarding the different preparatory measures invoked by South Korea and the United States, the country in which COVID-19 cases are most prevalent. We examine a plethora of statistics, such as the rate of spread and percent of people tested, in order to reach a holistic conclusion about the effectiveness of each country's mitigation strategy. In the third section we bring to light technological advancements that have been developed or are under development that have immense potential for application in virus detection, prevention, and mitigation.
\end{abstract}

Keywords-coronavirus, statistics, policy, United States, South Korea

\section{EPIDEMIOLOGICAL BACKGROUND}

An epidemic is any type of outbreak that has spread over a large geographical region. Well- known examples include the Zika virus, which originated in Brazil and later spread to the majority of Latin American and the Carribean [16], and the Ebola virus which originated and spread through West Africa. A pandemic is essentially an epidemic, but on a global scale. The most widely known pandemic in the past century is the 1918 Spanish influenza, or 'Spanish Flu,' which infected over $1 / 3$ of the world's population and resulted in approximately 50 million deaths. Since the Spanish flu, there have been various other pandemic outbreaks, such as the influenza pandemics of 1957 and 1968 and, more recently, the H1N1 (swine flu) pandemic in 2009 [1]

Pandemics have an immense impact on the global economy. During the aforementioned Spanish Flu pandemic, countless service-oriented businesses incurred "double-digit losses"; these ramifications exist in the current situation as well, as the coronavirus has ravaged industries ranging from restaurants to airlines to oil companies. The most apparent indicator of the damage the economy is suffering can be seen through the dramatic crash of the Dow Jones Industrial Average's (DJA) index value. On February 21, 2020, the index reached 28,992; in just over a month, it fell to 18,592 , the lowest it had been in years.

\section{A. H1Nl Pandemic of 2009}

Since the H1N1 pandemic is the most recent global pandemic, it was pragmatic to analyze the nature of its origin and spread. The H1N1 Pandemic is believed to have originated within pigs in a small region of Mexico [1]. Similar to the novel coronavirus, $\mathrm{H} 1 \mathrm{~N} 1$ is a virus transmitted through contact with respiratory droplets which are produced from person to person through sneezes or coughs. It is also possible to be infected by both the coronavirus and H1N1 by merely touching an object that has been in contact with respiratory droplets containing viral particles; as such, both are incredibly contagious, which is the basis for their prolific nature. The viral outbreak initially spread throughout the state of Veracruz, Mexico, in April of 2009 before spreading to the rest of the country and throughout the majority of the world by early 2010. The Mexican government attempted to contain the virus by shutting down the majority of the public and private facilities in Mexico City; however, the virus had become too widespread for their efforts to be effective.

The H1N1 outbreak officially reached the US on April 15, 2009, and went on to infect 60 million Americans, of which 12,500 passed away [1]. Within a week of the first reported case, the CDC activated its Emergency Operations Center, and by the end of the month the government had declared a public health emergency; as a result, the CDC started releasing medical supplies and drugs from their Strategic National Stockpile. In less than two weeks after the first case, the CDCdeveloped real-time Polymerase Chain Reaction (PCR) test was approved by the FDA. In addition to rapid production, the test was also extremely accurate, which is why it was shared with countries around the world.

Still, the H1N1 pandemic was considered an overall failure by the US to contain a viral infection as $1 / 5$ of the population ended up being infected [1]. Many critics of the mitigation effort noted America outdated and underfunded surveillance and research programs as being a large contributing factor, as well as poor leadership in times of a biological crisis. Additionally, the government was seen as not doing enough to prevent the spread of the virus, and instead focusing heavily on producing vaccines. However, the effort to vaccinate large swaths of the population failed largely due to an utter supply shortage once a vaccine had been developed. 


\section{B. COVID-19 Pandemic (2019-Present)}

COVID-19 is the name of the disease that is caused by the viral agent known as SARS-CoV-2 [6]. The CDC reports that it is thought to have originated in the city of Wuhan, China. The disease has caused the World Health Organization to declare a global public health emergency and officially classify the disease as the cause of a pandemic. Similar to previous coronaviruses, SARS-CoV-2 is originally found in bats and is generally consistent across different regions. COVID-19 can cause mild to severe illness that if becomes more severe, can cause pneumonia, organ failure, and death. Older people with historically compromised immune systems are at the highest risk of death from COVID-19. People with heart diseases, diabetes, lung disease, and other medical conditions are also at an increased risk of death. Symptoms of the disease include fever, dry cough, shortness of breath, and fatigue. The disease spreads through respiratory particles which are produced when an infected person either sneezes or coughs. These particles must be taken into the body through the nose, mouth, or eyes. The US government has advised people to stay at least 6 feet away from each other, and also to wear gloves when touching public objects as the virus can survive for prolonged periods of time on various surfaces as well. Currently, there is no vaccine or treatment for the virus, however significant progress has been made [6]. To date, COVID-19 has caused over 1.1 million deaths around the world, with approximately 223,000 of those being in the US and 453 being in South Korea.

The novel coronavirus has spread across 215 countries at the time of publication [6]. Many countries enacted massive international lockdowns with the goal of curbing the outbreak before it began to grow exponentially. Some countries, such as South Korea, have been relatively successful in accomplishing this goal; others, such as the United Kingdom and the United States, have performed and are currently performing poorly in containing and mitigating the virus. The global progression of the virus since the detection of the 50th case can be seen below.

Unfortunately, the US experienced significant exponential growth that was unprecedented around the world in the early stages of the outbreak. The multitude of reasons for this are presented in this paper, specifically in comparison to the South Korean model of early pandemic mitigation.

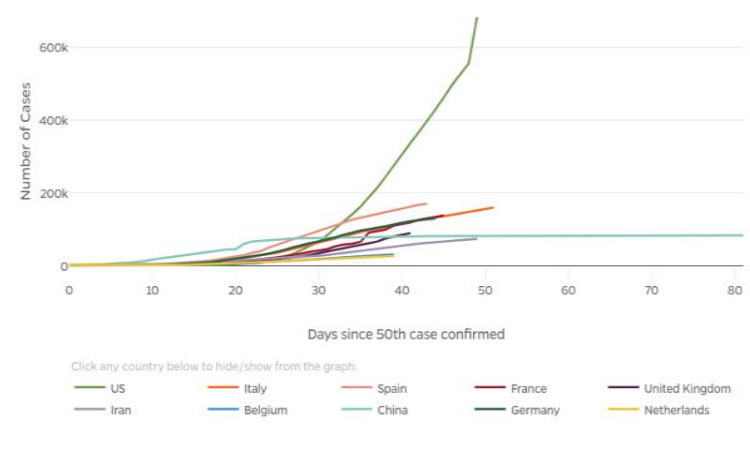

Fig. 1. Global COVID-19 Progression

\section{SOUTH KOREA}

South Korea was one of the first countries to experience the coronavirus epidemic, with its first case reported on January 20th, 2020; within a month, there were 346 confirmed cases, according to the Korean Centers for Disease Control and Prevention [22]. However, South Korea went on to implement what is largely considered to be the most organized and effective epidemic control program in the world, which resulted in the number of new infections flattening before rapid exponential growth could occur; moreover, South Korea accomplished this without implementing China's severe speech and movement restrictions or economically detrimental lockdowns as in the United States and Europe [14]. The effectiveness of South Korea's strategy can be conveyed by the number of new daily cases: on February 29th, medical workers reported 909 new cases; approximately one month later on March 22nd, a mere 64 new cases emerged [22]. We find that South Korea's strategy can primarily be condensed to the undertaking of expeditious action, extensive testing and contact tracing, and citizen support.

\section{A. Expeditious Action}

Much of South Korea's initial success in resisting coronavirus came from its experience in dealing with viral pandemics, such as in 2015 when a South Korean businessman brought Middle East respiratory syndrome (MERS) to Korea [18]. Upon diagnosis, he was treated and isolated; however, he had previously come in close contact with enough people to cause 186 infections and 36 deaths. Although these numbers are relatively minuscule in relation to the COVID-19 pandemic, South Korea was adamant to be prepared for the next viral outbreak. Since the MERS crisis occurred, South Korea has primarily focused on developing its pandemic mitigation infrastructure by building robust testing and data sharing capabilities. Specifically, the MERS outbreak led to amendments to the Disease Control and Prevention Act in order to provide the government a more optimized platform to rapidly respond to viral outbreaks by providing access to data without the need of a warrant in the event that a pandemic ensues. With these new laws came transparency, which invoked the public's "right to know" and required health officials to disclose information regarding viral transmission paths as soon as possible. The government also possesses the ability to immediately shut down any location that is deemed contaminated. Based on the relative success of the South Korean COVID-19 mitigation program, it can be concluded that these post-MERS legislative amendments have been effective.

South Korea initiated a swift and efficient response to the potential COVID-19 epidemic once it was discovered [5]. Within a week of South Korea's first coronavirus case being confirmed, several government officials met with medical companies to initiate the mass production of coronavirus test kits. Two weeks later, despite the country's confirmed cases remaining only in the double digits, thousands of test kits were being shipped each day; by early April, South Korea was producing upwards of 100,000 coronavirus tests per day.

Although South Korea avoided measures such as city-wide lockdowns, the government was in no way complacent. All infected individuals were mandated to self-quarantine and download an app that would immediately alert government officials if any infected citizen moved out of the quarantine [13]. Citizens determined to have been in contact with any 
infected individuals received emergency alerts on their phones with information about places to avoid and were required to self-quarantine as well. Furthermore, this was enforced by local monitoring teams, who made two daily calls to ensure people were following quarantine orders and to inquire about the progression of symptoms. Additionally, government officials swiftly enacted emergency measures in Daegu, a city of 2.5 million people that was the origin of South Korea's epidemic [14]. Scientists were able to discern early on the main source of infection, a church congregation, which minimized contagion.

South Korea's prompt handling of the situation has resulted in it having the lowest case fatality rate in the world from January to April, with just $2.1 \%$ of people contracting the illness dying; for comparison, the current global case fatality rate is $3.9 \%$ [15]. South Korea's low death rate from COVID19 can be attributed to its early mass testing program [22]. The benefits of this are twofold; further proliferation of the disease is prevented, and those already infected are treated sooner, both of which axiomatically reduce mortality rates.

\section{B. Extensive Testing and Contact Tracing}

The South Korean pandemic mitigation strategy is being touted as one of the most effective in the world [14]. Following the emergence of the coronavirus in mainland China, the KCDC began rapidly working with diagnostic manufacturers to develop commercially available test kits. The first test kit was approved on February 7 th, after which mass production began. This was despite the fact that, at the time, South Korea had very few positive cases [22]. Thousands of tests were produced and distributed to hospitals nationwide as a result of rapidly formed yet highly effective public-private. The move to begin early preparation soon paid off, as South Korea became the second most infected country after mainland.

On February 18th, an elderly South Korean woman tested positive for COVID-19 after attending a megachurch in the city of Daegu in which approximately 500 people sat shoulder to shoulder for two hours [22]. Within two weeks, South Korea had tested and identified nearly three thousand new cases, the majority of whom had been in attendance of the megachurch service, through contact tracing. Contact tracing is a process that follows a confirmed viral infection, in which all of the people that the infected individual could have come in contact with are rapidly tested for the virus. The method is one of the key features of combatting exponential viral transmission because it allows rapid and selective quarantining [14]. This strategy is especially pragmatic for South Korea, since a mass government-mandated lockdown is not viable or socially accepted in the country.

Following the initial outbreak mitigation through contact tracing, South Korea significantly ramped up its testing efforts. Public and private healthcare providers joined forces in order to establish more than 600 mobile testing sites that had the ability to test upwards of twenty thousand people per day by early March [30].

Apart from human viral transmission mitigation, South Korea's private technology sector rapidly developed infrastructure to be able to effectively warn citizens about locations in which a person who has tested positive visited [21]. The government also issued strong warnings to all citizens to wear gloves and masks while in public; however, self- quarantining is not mandatory except for those who have tested positive. Additionally, the South Korean Ministry of the Interior and Safety developed an app that provided a way for those who have confirmed infections to easily communicate with healthcare officials in order to report the progression of their symptoms; the app also allowed the government to temporarily track infected citizens in order to restrict them from breaking quarantine [13].

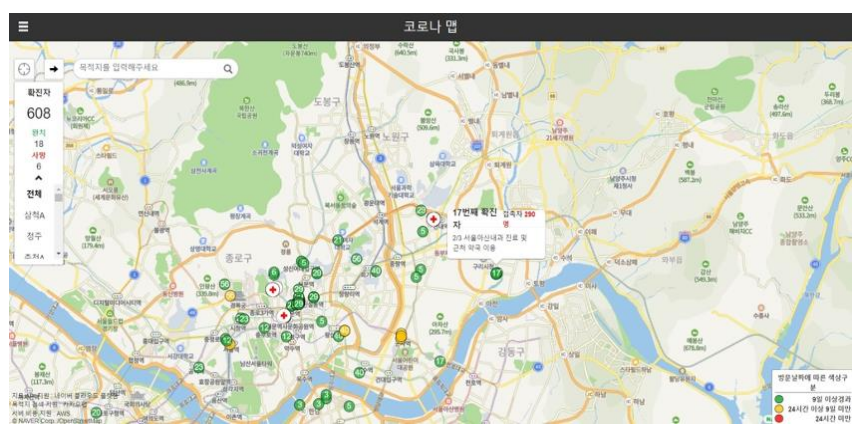

Fig. 2. Map of Potential COVID-19 Infection Sites from South Korean Contact Tracing App

\section{UNITED STATES OF AMERICA}

On January 21, the US reported its first confirmed case of COVID-19 in a patient that had recently traveled to Wuhan, China [6]. On February 26th, the US reported its first case of local transmission in California; shortly thereafter, additional cases were reported in Oregon, Washington, and New York. On that same day, two people died in the state of Washington, with the cause of death posthumously linked to COVID-19. The US federal government's early approach to dealing with the virus has faced heavy criticism for being inadequate in preventing the spread of the virus and seemingly prioritizing economic vitality over the well-being of its citizens [29]. Although the US did ramp up mitigation measures, the nation faced dire consequences in terms of fatalities and economic losses. A major source of struggle for America was applying contact tracing to the extent South Korea had, since the federal law does not have any special pandemic guidelines that allow for decisive action to be taken. Overall, the American approach to early pandemic mitigation has proven to be lackluster as a result of federal stagnation and the lack of a robust public-private partnership in the biomedical sector prior to the outbreak which consequently led to a massive lack of COVID-19 tests.

\section{A. Federal Stagnation}

Many of the shortcomings in the US's attempts to contain the pandemic stem the stagnation of the federal government. Specifically, it is well documented that approximately six weeks elapsed after the first case on US soil was detected before any aggressive nationwide measures were enacted. Additionally, the White House was repeatedly warned by numerous bureaucratic agencies and senior public health officials that COVID-19 was a potentially devastating virus; however, the executive branch generally chose to ignore the advised precautions and instead assured the American public that the virus would subside naturally, with President Trump even saying that it would disseminate "like a miracle" [29]. This narrative regarding the pathogenesis of the viral disease contributed significantly to its spread [23]. 
In the early months of pandemic, the White House generally disregarded field expert recommendations for spread mitigation, instead opting to continue to attempt to advocate that the situation was under control. Indeed, the National Security Council office, which is responsible for tracking pandemics, received intelligence reports in early January that predicted the spread of the virus to the US [32]. Following these initial reports, the NSC put together multiple plans with options that included the lockdown of urban centers and a temporary ban on working in offices. Peter Navarro, President Trump's trade advisor wrote a memo on January 29th that laid out the potential consequences of inaction in the face of the pandemic. Secretary of Health and Human Services, Alex Azar warned President Trump of a possible pandemic, to which President Trump responded by calling Azar an "alarmist." Despite this, Azar announced that the federal government would be creating a "surveillance system" in five US cities in order to measure the progression of the virus and collect more data for predicting its spread [29]. Unfortunately, this plan was subject to multiple bureaucratic roadblocks that postponed its implementation by weeks. By the time it was finally enacted, the virus had been spreading freely throughout the nation and the pandemic had begun. Finally, the top public health experts in the administration recommended that the President urge social distancing and staying home from work [9]. On the contrary, the White House chose not to enact these policies at the time of the recommendation, but rather chose to focus on convincing the public that the situation was under control.

President Trump eventually began recommending social distancing in mid-March, by which time the situation had descended into a full pandemic [9]. Multiple administration officials tried to defend the president's lack of action by stating that he was not presented with all of the necessary information until mid-March and that many of the sources in the White House that were providing him with intelligence information were "discredited" [29]; however, the numerous examples cited above prove otherwise. Between February 26th to March 16th, the date President Trump began pushing for social distancing, the number of detected cases grew from 15 to 4,226 , or 281 times larger.

One of the only policies that were imposed relatively early was a Chinese travel ban that was, which was finalized on January 31 [6]. However, it should be noted that the ban was still enacted after the first case had infiltrated the US, meaning that there were undoubtedly more. Had the ban been placed earlier, the strategy of containment would have been more possible and pragmatic.

\section{B. Lack of Media Coverage}

In the early stages of the global pandemic, the majority of main-stream American media outlets did not cover the threat of the pandemic with urgency. Indeed, many of the most popular news sources contributed to the complacency in January and February with regards to the coronavirus amongst the public, with many of them portraying the virus as something that was distant and inapplicable to the lives of Americans [9]. In fact, many news outlets pushed the public to not panic and instead to focus on dealing with the beginning of flu season. As a result, most Americans had not prepared physically or mentally for dealing with the pandemic once it started to grow in late February and early March. When the pandemic spread to countries beyond China, the American media began to take a more active stance in its coverage of COVID-19, however it was still not designated as an immediate threat by any major news agency. A contributing factor was that news corporations lacked true scientific information regarding the pathogenesis of the virus and its origin, Wuhan, China, as a result of a lack of government transparency.

Unfortunately, the knowledge that Wuhan is a major Chinese city with over 500 direct international flights per day (many of which were to the US) was not widely known until after cases began to show up in the US [32]. This inherent lack of contextualization of both the disease and its place of origin led most Americans to underestimate the virus's potential for damage. Additionally, the misconception that Americans should focus on the influenza rather than the coronavirus falsely portrays the latter as an entity that the vast majority of Americans would never come in contact. This, in combination with the federal government's lack of action and transparency, ultimately resulted in under-preparation by the American public and the rapid demise of the economy and institutions in the US.

\section{Inadequate Testing}

Epidemiological testing has been recognized as the key to pandemic mitigation throughout the world for decades. Adhanom Gebreyesus Tedros, the head of the World Health Organization stated that the only way to break the chain of transmission of a virus is through extensive testing [6]. Unfortunately, America largely ignored these global guidelines while they had the chance to prepare, and, as a result, scrambled to produce test kits of an adequate supply.

Towards the beginning of the pandemic, the US had one of the smallest stockpiles of tests prepared. The reasoning for this stems from the inherent lack of preparedness for pandemics that was present in the US, even before the COVID-19 outbreak [32]. Many field experts have argued that if the US had worked to have the proper infrastructure in place in preparation for a pandemic as opposed to a response to one, they could have quickly ramped up test manufacturing and applied the necessary course of action in terms of easing regulations and coordinating with the private sector to mitigate the crisis [19]. The absence of this type of robust infrastructure is reflected in the federal government's lackluster testing strategy.

In early February, the federal government began to implement its initial plan for widespread test manufacturing. On February 6th and 7th, the CDC shipped test kits out to multiple public labs around the country; subsequently, they received numerous complaints regarding faulty diagnostics, traced to an incorrect ingredient being used in the test kits [25]. This mistake took weeks to correct, resulting in the loss of almost the entire month of February. Furthermore, federal officials discouraged hospitals from developing and using their own testing kits, requiring them to gain FDA permission to do so instead. These two failures in cohesion led to almost no testing occurring in the month of February, meaning that public health officials had little data upon which to base policy decisions. 
Another possible miscalculation by the CDC has to do with testing criteria itself. The CDC criteria for testing for COVID19 originally only included people who had recently traveled to China or people that had been in direct contact with someone that tested positive for COVID-19 [6]. Since there were only a small number of confirmed cases at the time of these guidelines, CDC officials believed that they had produced an adequate amount of tests. The clear misconception in this reasoning is that it is impossible to truly know how many people have been infected the virus without conducting large scale testing. Moreover, it took until early March for the CDC to permit the use of a test when a physician suspected the virus in one of their patients, by which time many patients that had visited doctors in fears of coronavirus had been allowed to leave as a result of an inability to test them. Although testing capabilities had improved by April, with the US administering between 150,000 to 200,000 tests per day, the majority of experts in the field say that this was nowhere near the optimal amount which is upwards of 500,000 tests per day.

\section{STATISTICS BASED EFFICACY ANALYSIS OF} EARLY PANDEMIC MITIGATION STRATEGIES

We begin by analyzing the effectiveness of South Korea's early pandemic mitigation as depicted in the following figures. As Figure 3 shows, the rate of new COVID-19 infections has decreased significantly since the start of the epidemic in South Korea. Within just 40 days of the peak, the number of daily new cases had decreased from 851 to 32 .

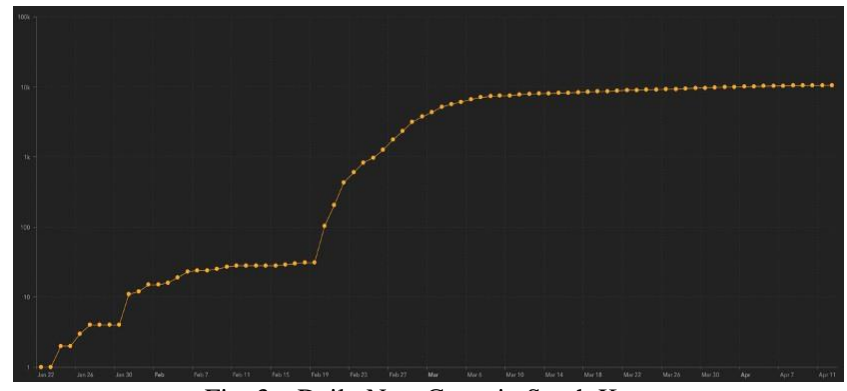

Fig. 3. Daily New Cases in South Korea

The number of confirmed cases, presented on a logarithmic scale in order to more adequately depict the rate of infection, can be seen in Figure 4. In accord with Figure 3, there was a significant slowing in the rate of new cases following the peak on March 3rd, 2020.

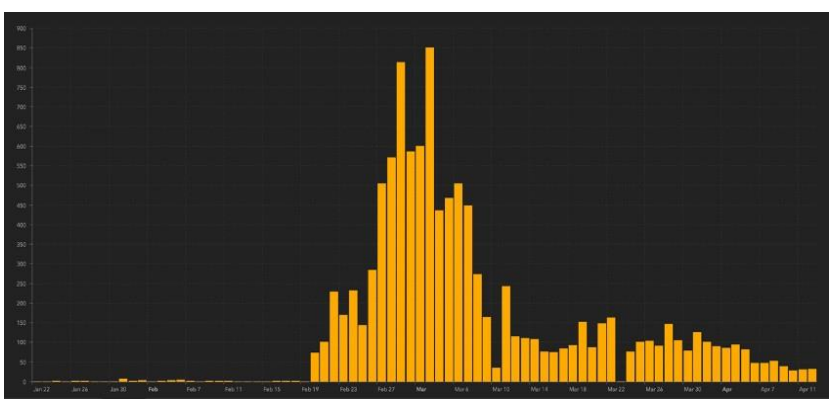

Fig. 4. Confirmed Cases in South Korea on a Logarithmic Scale

These numbers are notable when considering that South Korea has a population density of 503 people $/ \mathrm{km} 2$; this is approximately 14 times as high as the United States, which has a population density of 36 people/ $/ \mathrm{km} 2$. This difference in population density greatly increases the incidence rate of the virus in South Korea and would theoretically encourage greater proliferation as compared to the US.

The disparities in testing, as explained in previous sections, are significant indicators in predicting the progression of the virus and providing reasoning for its past trajectory. As mentioned above, South Korea has had one of the most well planned and implemented COVID- 19 mitigation strategies in the world. This is in spite of a population that is rapidly aging at unprecedented [27]. People older than 65 account for more than $14 \%$ of the population, outnumbering children. The low fatality rate can be attributed to the increased preparedness of South Korean hospitals in comparison to American hospitals. At the start of 2020, South Korea was reported as having 12.3 hospital beds per 1000 people, whereas the US had only 2.8 hospital beds per thousand people [2]. As a result of this, it was projected that 21 American states would fall short of the necessary ICU beds as COVID-19 progressed. States such as New Jersey and Massachusetts were projected to have 10 times less ICU beds than would be required in the coming weeks. This shortage of ICU beds would lead to thousands of deaths, as predicted in Figure 5, where the size of each circle represents the state population.

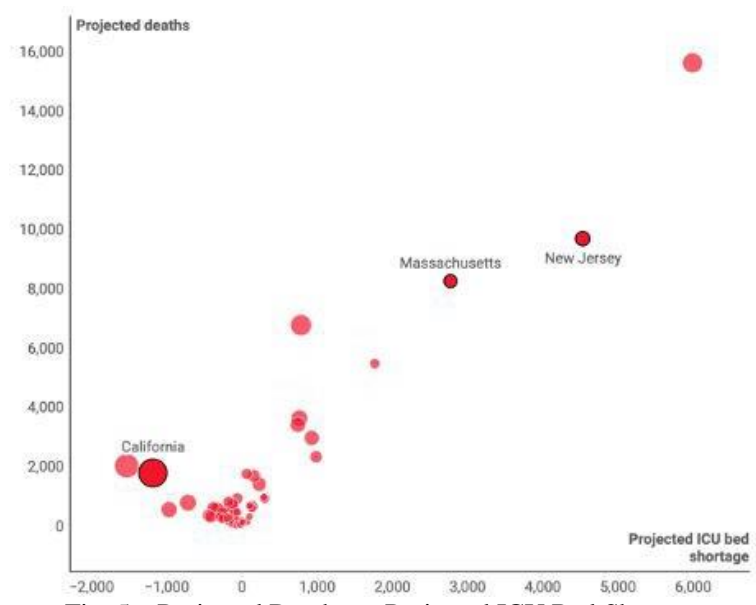

Fig. 5. Projected Deaths vs Projected ICU Bed Shortage

Perhaps the best indicator of South Korea's effectiveness comes from its low incidence rate, which was just 20.55 per hundred thousand people in April. At the same time, New York, one of the hotspots of the outbreak, had an incidence rate of $1,128.57$ per hundred thousand people, which is approximately 55 times as high as that of South Korea.

Despite the US and South Korea reporting their first confirmed coronavirus case on the same day, the US remained behind in terms of the total amount of tests conducted until the end of March. By the end of March, 1 in 142 South Koreans had been tested, whereas only 1 in 786 people had been tested in America [24]. 
As Figure 6 shows, though the outbreak initiated in late January, the infected curve began to flatten by the end of February. However, due to inadequate containment measures, the number of cases rose dramatically in March, reaching over 500,000 people.

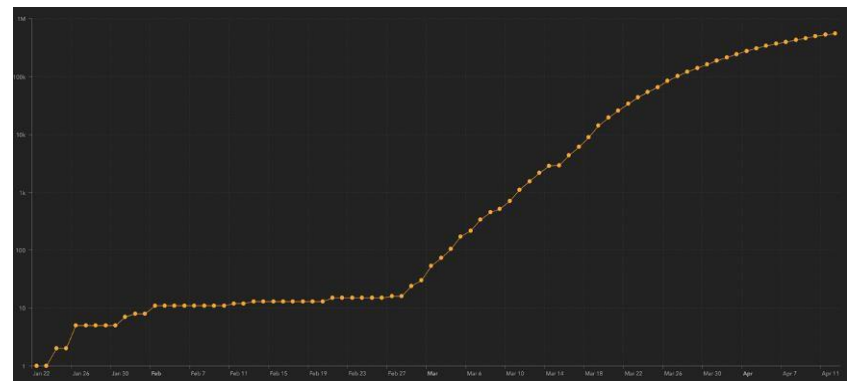

Fig. 6. Logarithmic Graph of Confirmed Cases in the US

Congruous with Figure 7, the number of new cases per day grew exponentially around the beginning of March in the US. The graph appeared to taper off towards the beginning of April, an effect of the recently implemented national guidelines of social distancing and self- quarantine.

Fig. 7. Daily Cases in the US

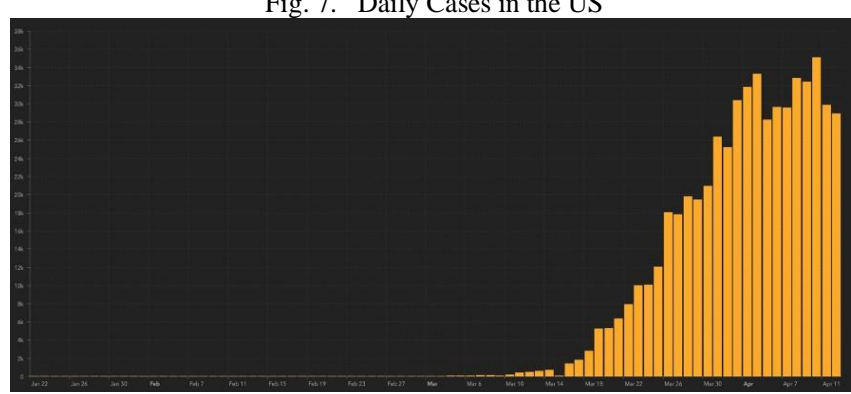

V. TECHNOLOGICAL ADVANCEMENTS

The novel coronavirus pandemic has prompted many cutting-edge solutions to help combat its spread. In China, where the virus originated, police wear thermal imaging helmets and goggles designed by $\mathrm{KC}$ Wearable that allow them to see people's body temperatures from five meters away [20]. When the headset notices someone who is unwell, it sets off an alarm to notify the police. The headset also features a camera that can read QR codes and Wi-Fi and Bluetooth capabilities so that it can transmit data to local hospitals; augmented reality is also incorporated in the visor to display a person's name and medical history by simply looking at them. Similar technology has also been implemented in unmanned aerial vehicles that use infrared temperature detection with image recognition to scan crowds and determine which people have fevers. This is not the only application of imagerecognition in China; Chinese technology firm Baidu Inc. developed an algorithm to discern subway commuters who evade wearing a mask properly [17].

South Korea has deployed private drone companies to spray disinfectant in public places, especially in the hardest-hit city, Daegu [17]. Disease control officials determine high-risk locations and then utilize these drones to spray disinfectant as a means to stop the pandemic. However, South Korea is perhaps more famous for its "Self-Quarantine Safety Protection" app. Those who have come into contact with people who tested positive for the coronavirus are mandated to download the app, which alerts local authorities if a person leaves their restricted quarantine area.

In Singapore, health officials have placed QR codes around the country in places such as taxis, offices, colleges, and tourist attractions [17]. These code direct them to a webpage where they enter their name and contact information, which allows authorities to reverse engineer an infected citizen's previous locations and people who they've come into contact with.

Biochemists at British biotech firm Virustatic have created a snood with "germ trap" technology [12]. The fabric coating is designed by attaching glycoproteins to carbon cloth in a similar formation to the carbohydrate structures on the surface of the cells in the esophagus. In addition to being a more ventilated and flexible option than traditional masks, the snood traps $96 \%$ of airborne viruses. Not only would this reduce viruses in the community, it would also be beneficial in the hospital environment. Currently, infected patients are unable to wear existing masks due to issues with breathability; however, the snood mask molds to each individual's face, providing maximum comfort for patients and safety for health workers.

Finally, in Denmark, Blue Ocean Robotics and Odense University Hospital have collaborated to launch the UV Disinfection Robot, a sterilizing machine with $360^{\circ}$ disinfection coverage that kills $99.99 \%$ of virus cells and bacteria using eight UV-C ultraviolet light bulbs [12]. This inflicts damage to the DNA and RNA of the viruses and harmful microbes, which inhibits their multiplication and spread. This is an efficient alternative to the current sterilization method via hydrogen peroxide; however, this requires hospital rooms to be left empty for several hours at a time, which is an impractical condition during a health crisis.

\section{CONCLUDING REMARKS AND ANALYSIS}

In our holistic analysis of the American and South Korean pandemic mitigation efforts, some key conclusions can be reached. The most important has to do with preparatory measures; in a world that is more interconnected than it has ever been before, all novel viral agents should be seen as holding the potential to result in a pandemic regardless of where they begin. The world will undoubtedly be a changed place once this pandemic subsides, and there will likely be a great increase in caution taken by federal governments around the world in terms of dealing with viruses. Specifically, based upon the literature reviewed, it can be advised that countries should continuously be working to develop a strong partnership in the biomedical sector in order to have the infrastructure developed and organized in the event of a pandemic. According to the majority of health experts, countries around the world should immediately impose strict travel bans when a country begins to experience any type of viral infection that holds the potential of evolving into a pandemic. Moreover, health officials should be consistently monitoring the potential viral agents that could be dangerous and should closely monitor domestic farm animals that often are the sources of such infections. Specific to the US, America ought to look at the coronavirus as a much needed revelation in the face of the now fully globalized world. Though this realization should have occurred with the H1N1 epidemic, the 
lessons learned from this pandemic will hopefully lead to extensive policy change in advance of the next pandemic.

South Korea's success in the mitigation of the virus and the early flattening of the curve comes from a multitude of factors. Firstly, the nation of 50 million began preparing thousands of test kits as soon as information regarding a novel virus was documented. The government was in contact with the leading biomedical companies in the nation within a week of being notified of the risk of the virus and had rapidly set up the infrastructure for the production of hundreds of thousands of tests. Another key to their success is in their contact tracing efforts. Since the government had amended the Disease Control and Prevention Act following the MERS epidemic, they had no bureaucratic hindrances and had a clear plan of action before the virus even reached South Korea. The Koreans' successful application of contact tracing coupled with their use of common technology to communicate with citizens had allowed them to quickly protect their citizens. Their strict enforcement of quarantine laws prevented patients with confirmed cases from spreading the disease, which is why the curve flattened at such a rapid rate. South Korea accomplished a huge reduction in coronavirus cases early on without instituting a nationwide lockdown, which is significant considering the country's extremely high population density. The South Korean mitigation effort should be used as a model for nations around the world in order to mitigate crises as fast as possible in the future.

Apart from comparing the mitigation strategies utilized by the US and South Korea, we looked into notable technological developments that could prove to be highly impactful in the future of epidemiology. These include China's fever-detecting headsets, South Korea's disinfecting drones, Britain's germ trapping snood, and Denmark's bacteria-killing robot. These groundbreaking advancements are not only beneficial to the current pandemic, but will have a lasting impact for years to come as they redefine healthcare.

\section{REFERENCES}

[1] 2009 H1N1 Pandemic (H1N1pdm09 virus). (2019, June 11). Retrieved August 01, 2020, from https://www.cdc.gov/flu/pandemicresources/2009-h1n1-pandemic.html

2] Aleem, Z. (2020, March 14). The US needs a lot more hospital beds to prepare for a spike in coronavirus cases. Retrieved October 23, 2020 from https://www.vox.com/science-andhealth/2020/3/14/21179714/coronavirus-covid-19-hospital-beds-china

[3] Anonymous. (2020, March 19). Danish disinfection robots save lives in the fight against the Corona virus. Retrieved August 01, 2020, from https://ec.europa.eu/digital-single- market/en/news/danish-disinfectionrobots-save-lives-fight-against-corona-virus

[4] Apple and Google partner on COVID-19 contact tracing technology. (2020, July 10). Retrieved August 01, 2020, from https://www.apple.com/newsroom/2020/04/apple-and-google-partneron- covid-19-contact-tracing-technology/

[5] Cho, H. (2020). Effectiveness for the Response to COVID-19: The MERS Outbreak Containment Procedures. Osong Public Health and Research Perspectives, 11(1), 1-2. doi:10.24171/j.phrp.2020.11.1.01

[6] Coronavirus Disease 2019 (COVID-19). (n.d.). Retrieved August 01, 2020, from https://www.cdc.gov/coronavirus/2019-ncov/index.html

[7] Early Release - Contact Tracing during Coronavirus Disease Outbreak South Korea, 2020 - Volume 26, Number 10-October 2020 - Emerging Infectious Diseases journal - CDC. (n.d.). Retrieved August 01, 2020, from https://wwwnc.cdc.gov/eid/article/26/10/20-1315 article

[8] DJIA.US | Dow Jones Industrial Average Stock Prices and Charts - WSJ (n.d.). Retrieved August 01, 2020, from https://www.wsj.com/marketdata/quotes/index/US/DJIA
[9] Green, T. \& Tyson, A. (2020, July 27). 5 facts about partisan reaction to COVID-19 in the U.S. Retrieved August 01, 2020, from https://www.pewresearch.org/fact-tank/2020/04/02/5-facts- aboutpartisan-reactions-to-covid-19-in-the-u-s/

[10] Hao, K. (2020, April 9). Here are the states that will have the worst hospital bed shortages. Retrieved from https://www.technologyreview.com/2020/04/07/998527/coronavirusus-states- worst-hospital-bed-shortages/

[11] History of Ebola Virus Disease. (2018, September 18). Retrieved Augus 01, 2020, from https://www.cdc.gov/vhf/ebola/history/summaries.html

[12] Kendrick, S. (2020, April 14). Rhyl GP surgery invest in 'germ-trap' snoods as they step up fight against Covid-19. Retrieved August 01 2020, from https://www.rhyljournal.co.uk/news/18373032.rhylsclarence-medical-surgery-invest-virustatic- shield-snoods-implementchanges-fight-covid-19/

[13] Kim, M. (2020, April 10). South Korea is watching quarantined citizens with a smartphone app. Retrieved August 01, 2020, from https://www.technologyreview.com/2020/03/06/905459/coronavirussouth-korea-smartphone- app-quarantine/

[14] Lee, D., \& Lee, J. (2020, April 21). Testing on the move: South Korea's rapid response to the COVID-19 pandemic. Retrieved August 01, 2020 from https://www.sciencedirect.com/science/article/pii/S2590198220300221

[15] Lin, R., II. (2020, March 07). What is the fatality rate for the new coronavirus, and why does it keep changing? Retrieved August 01, 2020 , from https://www.latimes.com/science/story/2020- 03-07/why-thecoronavirus-fatality-rate-keeps-changing

[16] Lowe, R., Barcellos, C., Brasil, P., Cruz, O., Honório, N., Kuper, H., \& Carvalho, M. (2018). The Zika Virus Epidemic in Brazil: From Discovery to Future Implications. International Journal of Environmental Research and Public Health, 15(1), 96. doi:10.3390/ijerph15010096

[17] Martin, T., \&amp; Lin, L. (2020, March 10). Fever-Detecting Goggle and Disinfectant Drones: Countries Turn to Tech to Fight Coronavirus. Retrieved August 01, 2020, from https://www.wsj.com/articles/fever detecting-goggles-and-disinfectant-drones-countries-turn-to- tech-tofight-coronavirus-11583832616

[18] Middle East Respiratory Syndrome (MERS). (2019, August 02). Retrieved August 01, 2020, from https://www.cdc.gov/coronavirus/mers/index.html

[19] Murthy BP, Molinari N-AM, LeBlanc TT, Vagi SJ, Avchen RN. Progress in public health emergency preparedness-United States, 2001-2016. Am J Public Health. 2017;107(S2):S180- S185.

[20] Nasajpour, M., Pouriyeh, S., Parizi, R., Dorodchi, M., Valero, M., \& Arabnia, H. (2020). Internet of Things for Current COVID-19 and Future Pandemics: An Exploratory Study. arXiv preprint arXiv:2007.11147v1

[21] Replication-Receiver. (2020, April 08). Korea's rapid innovations in the time of COVID-19. Retrieved August 01, 2020, from https://www.undp.org/content/seoul_policy_center/en/home/presscente r/articles/2019/korea_s- rapid-innovations-in-the-time-of-covid-19.htm

[22] Shim, E., Tariq, A., Choi, W., Lee, Y., \& Chowell, G. (2020, April). Transmission potential and severity of COVID-19 in South Korea Retrieved August $\quad 01, \quad 2020, \quad$ from https://www.ncbi.nlm.nih.gov/pmc/articles/PMC7118661/

[23] Subramaniam, T., Hickey, C. (2020, September 16). Timeline: Trump's public comments on Covid-19 vs. what he told Woodward in private. Retrieved October 23, 2020, from https://www.cnn.com/interactive/2020/09/politics/coronavirus-trumpwoodward-timeline/

[24] Subramaniam, T., \& Lybrand, H. (2020, March 26). Fact Check: US has done more coronavirus tests than South Korea, but not per person. Retrieved October 23, 2020, from https://www.cnn.com/2020/03/25/politics/coronavirus-testing-trumpsouth-korea-fact- check/index.html

[25] The lost month: How a failure to test blinded the US to COVID-19. (2020, March 30). Retrieved from https://economictimes.indiatimes.com/news/international/worldnews/the-lost-month-how- a-failure-to-test-blinded-the-us-to-covid19/articleshow/74876897.cms

[26] Tuckerhiggins. (2020, March 23). Here's everything the federal government has done to limit the economic destruction of coronavirus. Retrieved from https://www.cnbc.com/2020/03/23/trump- fed-congressgovernment-efforts-to-contain-coronavirus-economic-impact.html

[27] U.S. and World Population Clock. (n.d.). Retrieved October 23, 2020, from https://www.census.gov/popclock/ 
[28] Wainwright, O. (2020, March 25). 10 Covid-busting designs: spray drones, fever helmets, anti- virus snoods. Retrieved from https://www.theguardian.com/artanddesign/2020/mar/25/10coronavirus-covid-busting-designs

[29] Wallach, P., \& Myers, J. (2020, April 01). The federal government's coronavirus actions and failures. Retrieved August 01, 2020, from https://www.brookings.edu/research/the-federal- governmentscoronavirus-actions-and-failures-timeline-and-themes/

[30] Weible, C., Nohrstedt, D., Cairney, P., Carter, D., Crow, D., Durnová, A., ... Stone, D. (2020, April 18). COVID-19 and the policy sciences:
Initial reactions and perspectives. Retrieved August 01, 2020, from https://www.ncbi.nlm.nih.gov/pmc/articles/PMC7165254/

[31] What you need to know about COVID-19 Coronavirus Disease. (n.d.). Retrieved from https://www.cdc.gov/coronavirus/2019ncov/downloads/2019-ncov-factsheet.pdf

[32] Zenko, M. (2020, March 25). The Coronavirus Is the Worst Intelligence Failure in U.S. History. Retrieved from https://foreignpolicy.com/2020/03/25/coronavirus-worst-intelligencefailure-us- history-covid-19/ 